läre Subtyp auf (16\%). In 47\% der Fälle fanden sich in Gruppe A unklassifizierbare bzw. spitzoide Tumoren. In Gruppe B war die Mehrzahl der Melanome unklassifiziert (53\%).

92\% der Melanome aus Gruppe A wiesen zum Zeitpunkt der Diagnose mindestens ein Stadium IIA auf. In Gruppe B fielen $46 \%$ der Tumoren in diese Kategorie. Bei $82 \%$ der jungen Patienten hatte es von der Entdeckung der Läsion an ein halbes Jahr oder länger gedauert, bis die Diagnose gestellt war.

Am Ende der Beobachtungszeit von 36 Monaten waren $94 \%$ der Patienten aus Gruppe A und 82\% der Patienten aus Gruppe B noch am Leben. 67\% bzw. 63\% waren krankheitsfrei.

Fazit: Die Autoren der Studie schlagen vor, das ABCD-Schema für Kinder zu ändern: A müsse für Amelanose stehen und B solle blutende bzw. „bucklige“ (papulonoduläre) Läsionen bedeuten. C steht demnach für uniforme Colorierung. D wäre als beliebiger Durchmesser sowie als De-novo-Entstehung zu deuten. Das Kriterium E für „evolution“ (Wachstum und Entwicklung der Läsion) trifft nach den Autoren dagegen unabhängig von der Altersgruppe zu.

Dr. Robert Bublak

Cordoro KM et al. Pediatric melanoma: Results of a large cohort study and proposal for modified ABCD detection criteria for children. J Am Acad Dermatol 2013 Feb 7 [Epub ahead of print]

\section{Raumforderung seit fünf Jahren}

Eine 45-jährige Frau stellte sich wegen einer schmerzlosen submukösen Schwellung am rechten Zungenrand vor. Die Vorwölbung hatte sich im Lauf der letzten fünf Jahre allmählich vergrößert.
D alpatorisch lag eine nicht dolente, weiche kugelförmige Raumforderung von etwa $2 \mathrm{~cm}$ Durchmesser an der rechten Zungenhälfte vor, die Zungenoberfläche war unverändert.

Unter der klinischen Verdachtsdiagnose eines Lipoms wurde der Tumor exzidiert. Er hatte das umgebende Gewebe nicht infiltriert und konnte in toto herausgeschält werden (Abbildung).

Histologisch bestätigte sich die klinische Verdachtsdiagnose, die Wunde heilte komplikationslos ab. Im Lauf einer zweijährigen Nachbeobachtungs- periode kam es bisher nicht zu einem Rezidiv.

Fazit: Lipome gehören zu den häufigsten benignen Neoplasien. Im Bereich der Mundhöhle sind die häufigsten Lokalisationen die Wangenschleimhaut und die Zunge. Differenzialdiagnostisch war in diesem Fall auch an eine Dermoidoder Epidermoidzyste, ein Schwannom oder eine lymphoepitheliale Zyste zu denken.

Prof. Dr. Hermann FüeßI
Boffano P, Gallesio C. Lipoma of the tongue.

New Engl J Med 2013; 368: e37
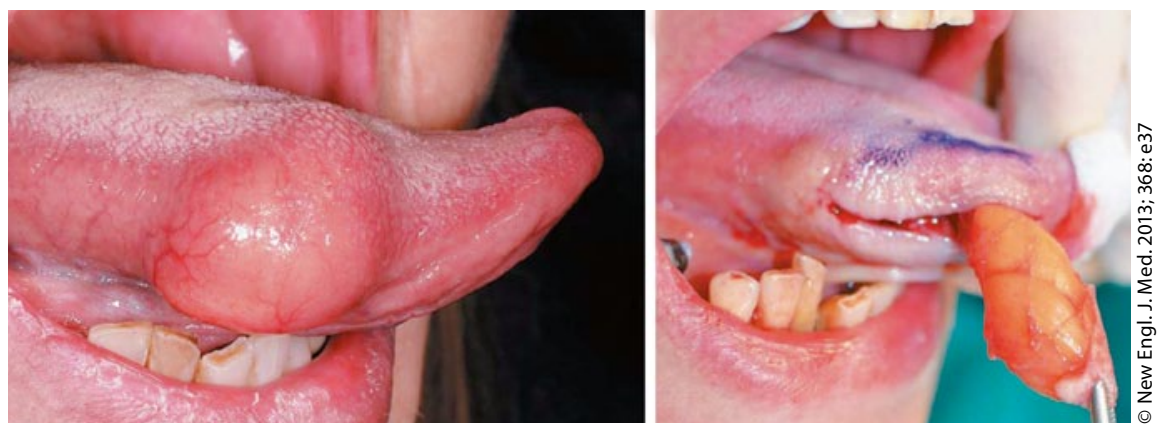

Raumforderung an der Zunge (links) und Tumorexzision (rechts).

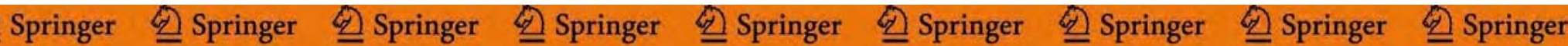

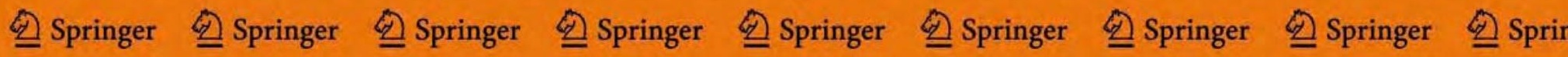

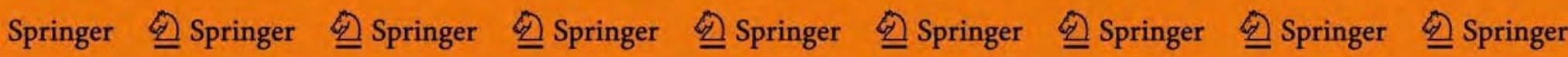

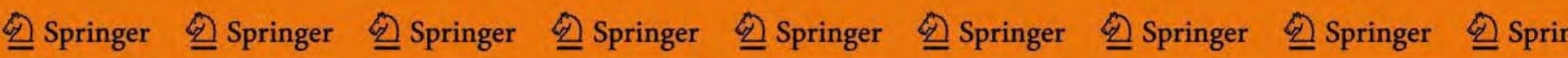

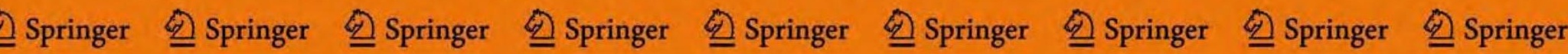

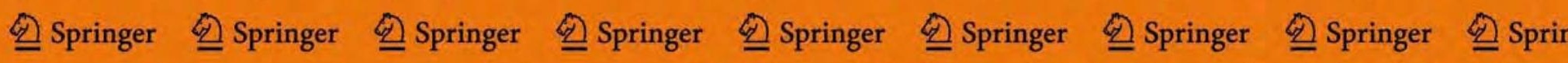

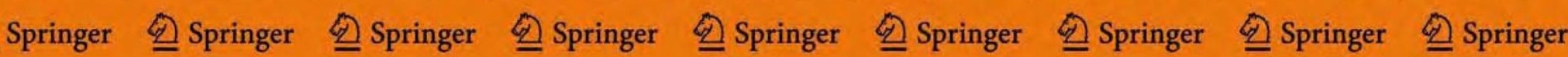

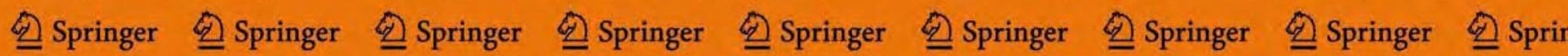

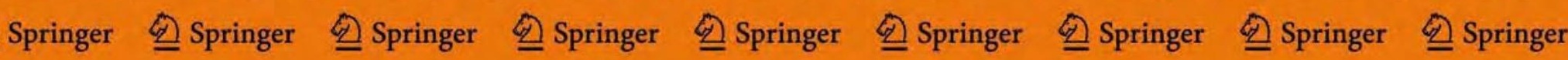

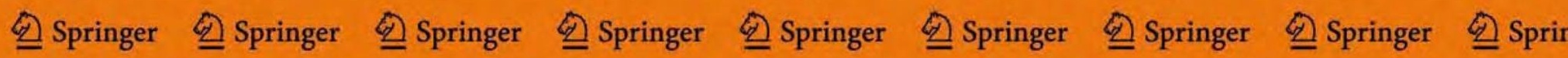

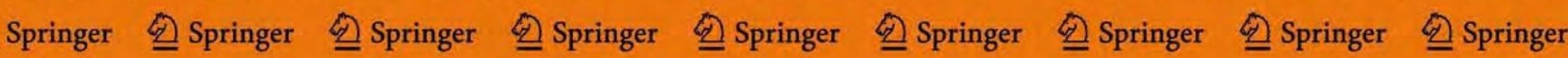

